\title{
Basement membrane extract attenuates the more malignant gene expression profile accentuated by fibronectin in prostate cancer cells
}

\author{
Bruno Martinucci ${ }^{1} \cdot$ Brenda de Carvalho Minatel $^{1} \cdot$ Maira Smaniotto Cucielo $^{1} \cdot$ Mariana Medeiros $^{1}$. \\ Ivan José Vechetti-Junior ${ }^{1}$ · Sérgio Luis Felisbino ${ }^{1}$ · Flávia Karina Delella ${ }^{1}[$
}

Received: 18 December 2017 / Accepted: 26 June 2018 / Published online: 30 June 2018

(c) Springer Science+Business Media, LLC, part of Springer Nature 2018

\begin{abstract}
Prostate cancer (PCa) has high mortality rates, with most of the deaths resulting from the development of metastasis. Fibronectin (FN) plays key roles in cell adhesion and affects the migratory behavior of cells. In the tumor microenvironment and also in the blood plasma during metastasis, FN displays increased expression, however its role in prostate cancer remains poorly understood. This study aimed to unveil the specific roles of FN as a soluble component, alone or in combination with a complex basement membrane. To investigate the impact of FN in neoplastic prostate cells, we evaluated the gene expression of LNCaP cells by RT-qPCR after exposure to soluble FN $(25 \mu \mathrm{g} / \mathrm{mL})$ either alone or in combination with a basement membrane. When FN was the predominant matrix element, such as in blood plasma, PCa tumor cells increased their expression of genes related to an invasive behavior and resistance to apoptosis, including CDH2, ITGA5, AKT1, and BCL2. However, the combined presence of FN and a complex basement membrane had the opposite effect on LNCaP cells, in which the expression levels of $C D H 2$, ITGA5, AKT1, and BCL2 were reduced. Hierarchical clustering analysis with LNCaP and RWPE-1 cells showed that LNCaP cells exposed to an enriched extracellular matrix displayed an expression pattern more similar to that shown by RWPE-1 cells, a cell line that illustrates characteristics of the normal prostate epithelium. These findings provide the groundwork for future studies addressing the role of FN in tumor growth, particularly in the context of cancer evolution/progression from a solid primary tumor to a transitory circulating state.
\end{abstract}

Keywords Fibronectin $\cdot$ Prostate cancer $\cdot$ Integrins $\cdot$ Cadherins $\cdot$ Metastasis $\cdot$ RWPE-1

\section{Introduction}

Prostate cancer ( $\mathrm{PCa}$ ) continues to be a leading cause of death among men worldwide [1]. Early diagnostic rates have increased with the onset of the prostate-specific antigen (PSA) test, allowing for great improvements in 5-year survival rates [2]. However, even with these advancements,

Bruno Martinucci and Brenda de Carvalho Minatel have contributed equally to this work.

Electronic supplementary material The online version of this article (https://doi.org/10.1007/s11010-018-3399-4) contains supplementary material, which is available to authorized users.

Flávia Karina Delella

fkdbio@gmail.com

1 Department of Morphology, Institute of Biosciences of Botucatu - Univ Estadual Paulista (Unesp), Botucatu, Sao Paulo, Brazil most PCa-related deaths still occur due to the development of metastasis [3].

Metastasis is a multi-step process mediated not only by genetic changes occurring within tumor cells, but also by physical remodeling of the tumor microenvironment $[4,5]$. The spread of cells to distant sites requires the involvement of stromal components, along with differential expression of molecules related to cell-cell and cell-matrix interactions [6-8]. To successfully disseminate themselves, tumor cells must be able to complete all of the following steps: (1) detach from the primary tumor mass; (2) degrade the basement membrane; (3) invade the stromal surrounding tissue; (4) intravasate into blood and lymphatic vessel lumens; and, finally, (5) disseminate and colonize other organs, such as lymph nodes, bones, lung, liver, and brain [9-12].

Once tumor cells have reached the blood stream, they activate the coagulation cascade and surround themselves with fibronectin (FN) molecules, forming a thrombus that protects them against the cytotoxic activity of immune cells 
$[12,13]$. The thrombus becomes a protective shield that stabilizes these circulating tumor cells and provides a favorable microenvironment that sustains cell adherence amongst each other and to the blood vessel wall, which will later be necessary for extravasation to the surrounding tissue [12-14]. Additionally, the FN-rich thrombus microenvironment has been shown to activate important intracellular signaling cascades via surface receptors, such as the AKT pathway, which mediates tumor survival [15].

FN is a multifunctional modular glycoprotein present in numerous tissues throughout the body, being an important component in blood plasma [16], as well as in connective tissue matrices [17]. High FN levels have been documented in diverse processes such as wound healing and arthritis, and many types of cancer [18-20]. With regard to PCa, however, there is limited data on FN expression levels in tissue samples and changes in serum FN concentration in patients [21], which have rather generated contradictory information about the role of FN in this disease.

Identifying and understanding the functions of $\mathrm{FN}$ in prostate tumor cells will provide insights into the mechanisms of $\mathrm{PCa}$ progression and metastasis. We therefore sought to evaluate the impact of FN on the expression of cadherins, integrins, and important genes involved in cell proliferation and survival (such as AR, AKT1, PTEN, STAT3, MYC, BCL-2 and BAX), using the LNCaP cell line as a model [22]. For this, the cell line was exposed: (1) only to $\mathrm{FN}$, mimicking the interactions between tumor cells and this molecule in the plasma; and (2) to FN in combination with a basement membrane extract, mimicking the interaction in primary tumors. We also investigated whether these exposures would approach or distance the expression of the evaluated genes between the neoplastic cell line (LNCaP) and a non-malignant cell line (RWPE-1).

\section{Materials and methods}

\section{Cell lines and culture conditions}

LNCaP and RWPE- 1 cells were purchased from the American Type Culture Collection (ATCC) and cultivated in standard cell culture medium optimal for each cell type. The LNCaP cell line (clone FGC - ATCC® CRL-1740 ${ }^{\mathrm{TM}}$ ) represents androgen-sensitive prostate adenocarcinoma, while RWPE-1 cell line (ATCC $\AA$ CRL-11609TM) is commonly used to represent the non-malignant growth. $\mathrm{LNCaP}$ cells were cultured in RPMI 1640 medium (Gibco ${ }^{\mathrm{TM}} ; 11875093$ ) supplemented with $10 \%$ fetal bovine serum (FBS; Gibco ${ }^{\mathrm{TM}}$; $16000044)$ and $1 \% 100 \times$ antibiotic/antimycotic $\left(\mathrm{Gibco}^{\mathrm{TM}}\right.$; 15240062). RWPE-1 cells were cultured in Keratynocite Serum Free medium $\left(\right.$ Gibco $\left.^{\mathrm{TM}} ; 37000015\right)$ supplemented with $0.05 \mathrm{mg} / \mathrm{mL}$ bovine pituitary extract, $5 \mathrm{ng} / \mathrm{mL}$ human recombinant epidermal growth factor, and $1 \% 100 \times$ antibiotic/antimycotic (Gibco $\left.{ }^{\mathrm{TM}} ; 15240062\right)$. All cell lines were maintained in a humidified incubator with $5 \% \mathrm{CO}_{2}$ at $37{ }^{\circ} \mathrm{C}$.

\section{Coating conditions}

Cells were seeded at $4 \times 10^{4}$ cells $/ \mathrm{cm}^{2}$ and all experiments were carried out in triplicate. The LNCaP cells were cultivated for four days under the following conditions: (1) standard medium - Non-exposed group; (2) exposed to $25 \mu \mathrm{g} / \mathrm{ml}$ FN from human plasma (Sigma-Aldrich; F0895), according to an established protocol previously published by our group [23]; (3) plates coated with a basement membrane extract (Geltrex ${ }^{\circledR}$ Reduced Growth Factor Basement Membrane Matrix) (Gibco ${ }^{\mathrm{TM}}$; A1569601) plus FN diluted in the medium $(25 \mu \mathrm{g} / \mathrm{ml})$; and (4) plates coated with Geltrex ${ }^{\circledR}$ without FN exposure. To coat the plates, Geltrex ${ }^{\circledR}$ was added, covering the entire well $\left(50 \mu \mathrm{L} / \mathrm{cm}^{2}\right)$ of the six-well plates $\left(9.6 \mathrm{~cm}^{2}\right)$, and the plates were incubated at $37{ }^{\circ} \mathrm{C}$ in $5 \% \mathrm{CO}_{2}$ for 30 min to allow polymerization. RWPE- 1 cells were cultivated only with standard medium, without coating.

\section{RNA extraction and CDNA synthesis}

RNA extraction was performed with the PureLink ${ }^{\circledR}$ kit (Ambion $^{\mathrm{TM}}$, catalog number 12183020) according to the manufacturer's instructions. RNA samples were quantified using NanoVue ${ }^{\mathrm{TM}}$ Plus spectrophotometer (GE HealthCare), and sample quality was assessed with an Agilent 2100 Bioanalyzer (Agilent Technologies) [24]. Only samples with RNA integrity numbers above 9 were used for further analysis. To remove genomic DNA, we used the TURBO DNAfree $^{\mathrm{TM}} \mathrm{Kit}$ (Ambion ${ }^{\mathrm{TM}}$, AM1907) and $1 \mu \mathrm{g}$ of RNA was reverse-transcribed into cDNA, using SuperScript ${ }^{\circledR}$ VILO $^{\mathrm{TM}}$ Master Mix (Invitrogen ${ }^{\mathrm{TM}}$; catalog number 11755500).

\section{Quantitative real-time polymerase chain reaction (RT-qPCR)}

For RT-qPCR, the QuantStudio ${ }^{\mathrm{TM}}$ 12K Flex system (Applied Biosystems) was used. The cDNA samples to quantify: AKT serine/threonine kinase 1 (AKT1), BCL2 associated $\mathrm{X}$ (BAX), BCL2, E-cadherin (CDH1), N-cadherin (CDH2), integrin subunit beta 1 (ITGB1), MYC proto-oncogene (MYC), phosphatase and tensin homolog (PTEN), and signal transducer and activator of transcription 3 (STAT3) mRNAs were amplified using TaqMan® Fast Advanced Master Mix (Applied Biosystems ${ }^{\mathrm{TM}}$; 4444557) and TaqMan ${ }^{\circledR}$ Gene Expression Assays (Applied Biosystems ${ }^{\mathrm{TM}}$; Supplementary Table 1). For the Androgen Receptor (AR), integrin subunit beta 3 (ITGB3), integrin subunit alpha 5 (ITGA5), and integrin subunit alpha V (ITGAV) mRNAs, the cDNA samples were amplified using Fast SYBR $®$ Green Master 
Mix (Applied Biosystems ${ }^{\mathrm{TM}}$; 4385617) and primers synthesized by Thermo Fisher Scientific (Supplementary Table 2). Relative gene expression was calculated via the $2-\Delta \Delta C_{\mathrm{t}}$ method [25] and normalized to the GAPDH gene expression $\left[C_{\mathrm{t}}\right.$ means $\pm \mathrm{SD}$ were as follows: (1) RWPE-1 cells: $27.826 \pm 0.07$; (2) $\mathrm{LNCaP}$ on uncoated plates: $27.178 \pm 0.18$; (3) LNCaP on Geltrex ${ }^{\circledR}$ coating: $27.509 \pm 0.13$; and (4) LNCaP on Geltrex ${ }^{\circledR}$ coating plus FN: $\left.27.337 \pm 0.09\right]$. For analyses involving only LNCaP cells, gene expression data was normalized using the mean expression values of nonexposed LNCaP cells $(n=3)$. For cluster analyses involving RWPE-1 and LNCaP cells, expression data was normalized for each gene, using the mean expression values of all groups $(n=12)$.

\section{Statistical analysis}

Statistical analyses were performed by a $t$ test or a parametric one-way ANOVA test with an a posteriori Tukey test. Differences were considered statistically significant at $p<0.05$.

\section{Results}

\section{Fibronectin enhances the expression of $\mathrm{N}$-cadherin and integrins $\alpha v \beta 3$ and $\alpha 5 \beta 1$}

The dissemination of tumor cells to distant organs begins with a transformation in phenotype, in which the cells shift from a benign to a malignant phenotype. In this multi-step process, epithelial cells that are normally cohesive, have to acquire migratory and invasive characteristics mediated by cell-adhesion molecules, such as cadherins and integrins [26]. Cadherins are important cell-surface glycoproteins that mediate cell-cell interactions and, studies have shown that a key event in tumor cell migration is the suppression of E-cadherin, and upregulation of N-cadherin [27]. In the other hand, integrins are surface receptors that mediate cell adhesion to the extracellular matrix (ECM), translating mechanical properties into intracellular biochemical signals [28]. Therefore, considering that integrins $\alpha v \beta 3$ and $\alpha 5 \beta 1$ are $\mathrm{FN}$ receptors and that $\mathrm{E}$-cadherins and $\mathrm{N}$-cadherins are crucial for tumor invasion, we sought to evaluate the ability of FN to affect the expression of these genes. For that, LNCaP cells were exposed to soluble FN in the concentration of $25 \mu \mathrm{g} / \mathrm{ml}$. The exposure to soluble FN decreased the expression levels of $C D H 1$ ( 0.62 fold) and increased the levels of $\mathrm{CDH} 2$ (1.98 fold), suggesting that soluble FN may support an invasive behavior. Additionally, we observed a significant increase in the expression of ITGA5 (2.70 fold), $I T G A V$ (2.81 fold), and ITGB3 (2.71 fold) after exposure to FN when compared with non-exposed cells (Fig. 1).

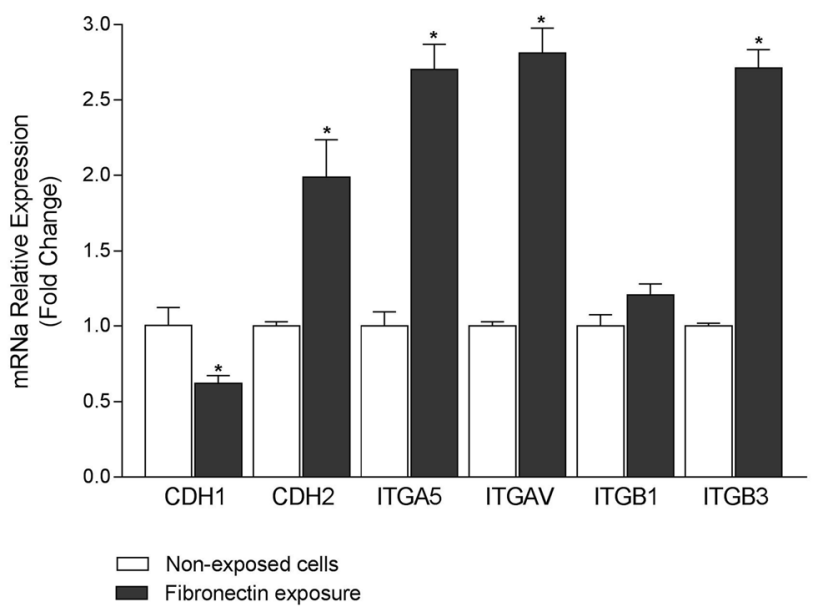

Fig. 1 Relative expression of cell surface receptors genes after FN exposure (fold change versusnon-exposed LNCaP cells). mRNA levels of cadherins and integrins in LNCaP cells: not exposed (white bars) or exposed (black bars). Values are expressed as mean \pm SEM; $* p<0.05$

\section{Fibronectin provides a pro-proliferative intracellular signaling stimulus}

The increase in cell proliferation rates and survival are also a crucial event for tumor progression. Cell-matrix interactions mediated by integrins have been shown to modulate these cellular processes by triggering alterations in intracellular signaling pathways [29]. Fibronectin has been shown to support cell survival by increasing Bcl-2 expression through interaction with integrin $\alpha 5 \beta 1$ in colon carcinoma and neuronal cells [30]. Therefore, to explore whether FN exposure also supports cell survival and proliferation in $\mathrm{PCa}$, we examined the expression of genes involved in cell signaling, proliferation and cell death pathways. Table 1 presents detailed Gene Ontology (GO) annotations and the major function of each evaluated gene.

After FN-only exposure, LNCaP cells showed significantly increased expression of pro-proliferative genes $A K T 1$ and MYC; while that of PTEN was reduced compared with that in the non-exposed cells. With respect to genes related to cell death, $B C L 2$ expression was highly increased, whereas that of $B A X$ showed a twofold decrease in expression when compared with that in the non-exposed cells (Fig. 2). As briefly mentioned, the genes $A K T 1$ and $M Y C$ support cell proliferation and survival, while PTEN has the opposite role, being a negative regulator of the PI3K-AKT/PKB signaling pathway [31]. Similarly, the $B C L 2$ gene suppresses apoptosis, while $B A X$ has pro-apoptotic functions [32]. Therefore, our results indicate that FN supports cell survival and proliferation in $\mathrm{PCa}$, corroborating with its roles in colon carcinoma and neuronal cells. 
Table 1 Gene ontology (GO) annotation and function of evaluated genes

\begin{tabular}{lll}
\hline Gene & Related GO annotation $^{\text {a }}$ & Function \\
\hline AR & Transcription factor activity and DNA binding & Cell signaling \\
AKT1 & Protein binding and protein kinase activity & Cell signaling \\
PTEN & Protein kinase binding and magnesium ion binding & Cell signaling \\
STAT3 & Transcription factor activity and DNA binding & Proliferation \\
MYC & Transcription factor activity and DNA binding & Proliferation \\
BCL2 & Protein homodimerization activity and protein binding & Death \\
BAX & Protein homodimerization and heterodimerization activity & Death
\end{tabular}

${ }^{\text {a}}$ Only the two main GO annotations are mentioned

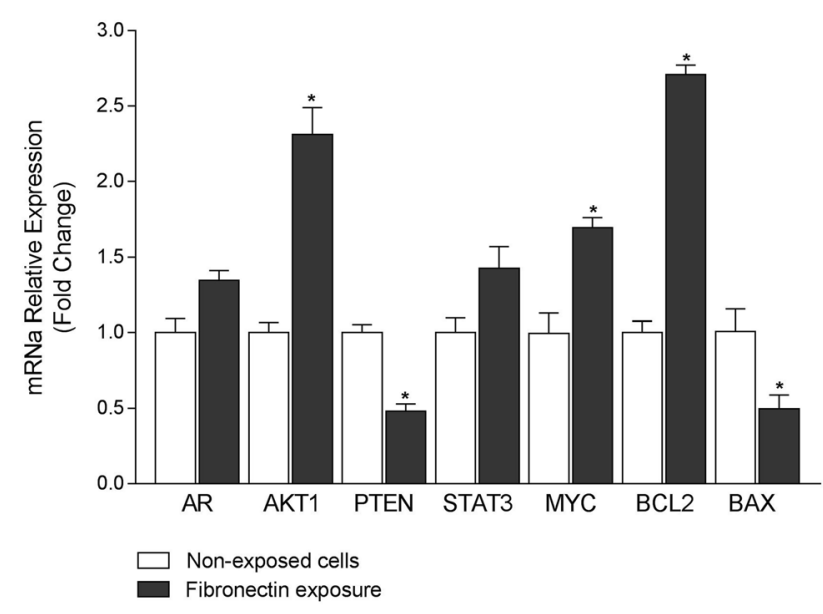

Fig. 2 Relative expression of genes related to pathways that transfer signals from the extracellular to the intracellular compartment (fold change versus non-exposed LNCaP cells). mRNA levels of genes related to cell signaling, proliferation, and survival were evaluated in LNCaP cells: non-exposed (white bars) or FN-exposed (black bars). Values are expressed as mean $\pm \mathrm{SEM} ;{ }^{*} p<0.05$

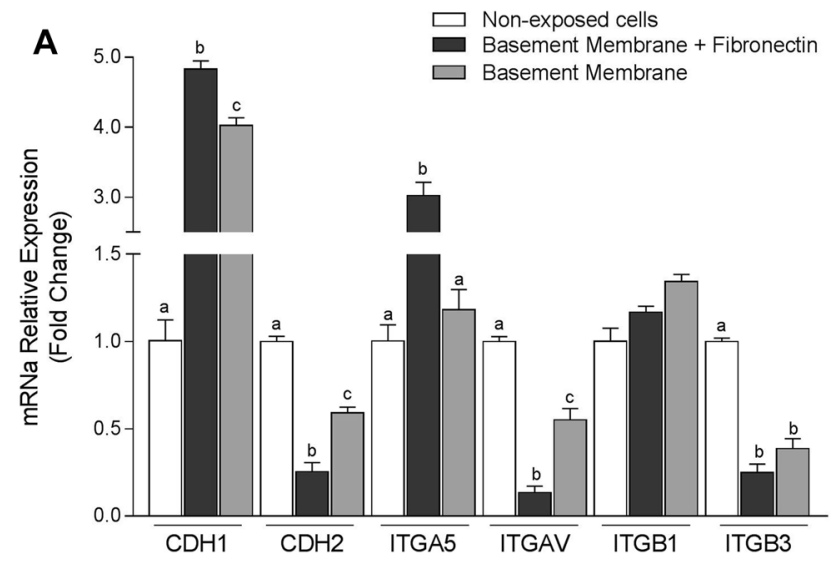

Fig. 3 Relative expression of cell surface receptors and genes involved in signal transduction from the extracellular to the intracellular compartment (fold change versus non-exposed LNCaP cells). mRNAs levels of cell surface receptors and genes related to cell signaling, proliferation, and survival were evaluated in LNCaP cells: non-

\section{Fibronectin inversely alters gene expression when combined with a basement membrane extract}

The ECM is a complex and highly dynamic structure that undergoes constant remodeling to precisely maintain its composition [33]. In the tumor setting, activated fibroblasts have been shown to alter the normal dynamic and composition of the ECM, supporting tumor progression [34]; while the exposure of tumor cells to a normal and balanced ECM is capable of restraining tumor progression [35]. Therefore, considering that each component of the ECM surrounding tumor cells play important roles in determining the cell's phenotype and behavior, we sought to evaluate if FN would have the same impact in LNCaP cells when present in an ECM-enriched environment, like those found in primary tumor sites. For that, we cultivated LNCaP cells on top of a basement membrane (Geltrex ${ }^{\circledR}$ ) with soluble FN diluted in the medium.

As seen in Fig. 3a, the combination of Geltrex ${ }^{\circledR}$ and FN led to a gene expression pattern opposite to that of the one

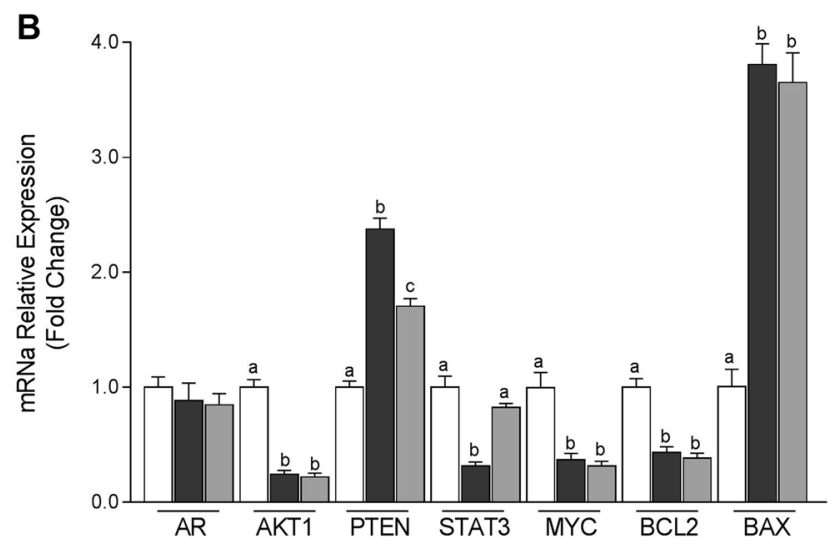

exposed (white bars), exposed to FN in combination with a basement membrane (black bars), and exposed only to basement membrane (grey bars). Values are expressed as mean \pm SEM. Bars with different letters are significantly different $(p<0.05)$ 
observed with only FN. In this case, $\mathrm{CDH} 1$ expression level showed an increase of 4.83-fold compared with that in the non-exposed cells. $\mathrm{CDH} 2$ that had previously displayed a markedly increase in its expression levels had a four-fold decrease in expression. For the integrins, both subunits of integrin $\alpha v \beta 3$ (ITGAV and ITGB3) had significantly decreased expression, while the expression of ITGA5 was increased. The integrin subunit $\beta 1$ had the same level of relative expression among all groups (Figs. 1, 3a).

Likewise, regarding the expression of genes related to cellular behavior, the presence of a more complex basement membrane shifted the gene expression observed following FN-only exposure (Fig. 3b). In this case, AKT, STAT3, MYC, and $B C L 2$ had significantly decreased expression by more than two-fold, when compared with that in the non-exposed cells; while PTEN and BAX showed significantly increased expression. All fold change values are presented in Supplementary Table 3 . Therefore, as expected, our results demonstrate that although the FN itself is capable of supporting a more invasive phenotype in tumor cells, when the cells are surrounded by a more balanced microenvironment this phenotype is restrained.

\section{Fibronectin exposure distances gene expression pattern between LNCaP and RWPE-1 cells}

In this study, we sought to assess how FN would affect the expression levels of genes associated with cell-cell/ cell-matrix interactions, cell proliferation and survival. More specifically, we aimed to evaluate if those expression changes would occur in a manner that resemble a more invasive and aggressive phenotype, or a more benign phenotype. For this, we compared the expression patterns of LNCaP cells cultivated under three different conditions: (i) non-exposed, (ii) exposed to FN, and (iii) exposed to FN in combination with a basement membrane, to the expression patterns of RWPE-1 cell lines (non-malignant cells) cultivated in a standard culture.

Hierarchical clustering analysis (Fig. 4) indicated a clear distinction among the groups, in which LNCaP cells exposed only to FN acquired a very distinct expression pattern when compared to RWPE-1 cells; while LNCaP cells exposed to the combination of FN with a more complex basement membrane showed an expression profile similar to the expression pattern of RWPE-1 cells.

\section{Discussion}

FN is one of the most abundant adhesion proteins in blood plasma [36], and has been shown to support stabilization and survival of circulating tumor cells in the blood stream during metastatic progression [12]. The role of FN in cancer is not yet fully understood; whereas some studies suggest that the adhesive activity of FN suppresses tumor cell invasion [18, $37,38]$, others indicate that FN may assist in the invasion and metastasis processes [12, 39-41].

During the metastatic process, tumor cells can interact with FN in two different environments: (1) in the primary tumor site, in which the cells are in contact with the FN present in the surrounding stromal microenvironment; or, (2) in blood plasma, where FN is an abundant soluble component $[41,42]$. The examination of samples from patients with PCa correlates high levels of FN and increased mortality, promoting $\mathrm{FN}$ as a prognostic biomarker for this cancer type [41]. In this study, we showed that exposure to only FN, mimicking the plasma environment, results in increased $\mathrm{N}$-cadherin $(\mathrm{CDH} 2)$ expression and decreased E-cadherin $(\mathrm{CDH1})$ expression, suggesting that plasma FN supports the acquisition of an invasive phenotype. Indeed, studies have demonstrated that $\mathrm{N}$-cadherin overexpression is associated with higher invasion rates and the development of an androgen-independent state in prostate tumor cell lines [43]. Changes in integrin expression can also be associated with such invasive behavior. Upregulation of integrins $\alpha 5 \beta 1$ and $\alpha v \beta 3$ has been associated with invasiveness in several cancers, as lung cancer and bone metastasis [44, 45].

Likewise, our findings showed increased expression of integrin subunits $\alpha 5, \alpha v$, and $\beta 3$ in FN-exposed LNCaP cells. Similar results found in lung cancer presented the activation of integrins $\alpha \mathrm{v} \beta 3$ by plasma FN, promoting premetastatic condition to cancer cells [12]. Together, our data indicate and reinforces using another cancer cell model that soluble FN may support the adhesion of tumor cells mediated by $\mathrm{N}$-cadherin (CDH2) and integrins $\alpha \mathrm{v} \beta 3$ and $\alpha 5 \beta 1$.

Because intracellular signals downstream of cell surface receptors are crucial for the processes of metastasis and anchorage-independence, we also evaluated the expression status of several genes important for regulating cell growth, proliferation, and survival. After FN exposure, LNCaP cells showed increased $A K T 1$ expression. $A K T$ is required for cell survival and studies have shown that FN can activate the AKT pathway, which could in turn contribute to the development of resistance to apoptosis in PCa cells [40]. Likewise, we detected a significant increase in BCL2 expression, an anti-apoptotic gene, and a significant decrease in $B A X$ expression, an apoptotic inducer gene. Functional studies have demonstrated that FN induces BCL2 expression with a consequent decrease in apoptosis rates [46-48].

Furthermore, $\mathrm{LNCaP}$ cells exposed only to $\mathrm{FN}$ displayed higher expression levels of $M Y C$, upregulation of which is related to early stages of $\mathrm{PCa}$, required for AR-dependent growth and related to the development of metastatic progression in $\mathrm{PCa}[49,50]$. Thus, we propose that when FN is the predominant element, tumor cells can develop invasive behavior and resistance to apoptosis. 
Fig. 4 Hierarchical clustering of gene expression data from RWPE-1 cells and LNCaP cells $(n=12)$. The clustering analysis was carried out using DESeq package (R/bioconductor) based on Euclidian distance. Expression data are normalized for each gene, using the mean expression of all samples, and scaled to $Z$-scores of the rows in order to show differences among samples for each gene. Blue boxes indicate lower levels; red boxes indicate higher levels. (Color figure online)

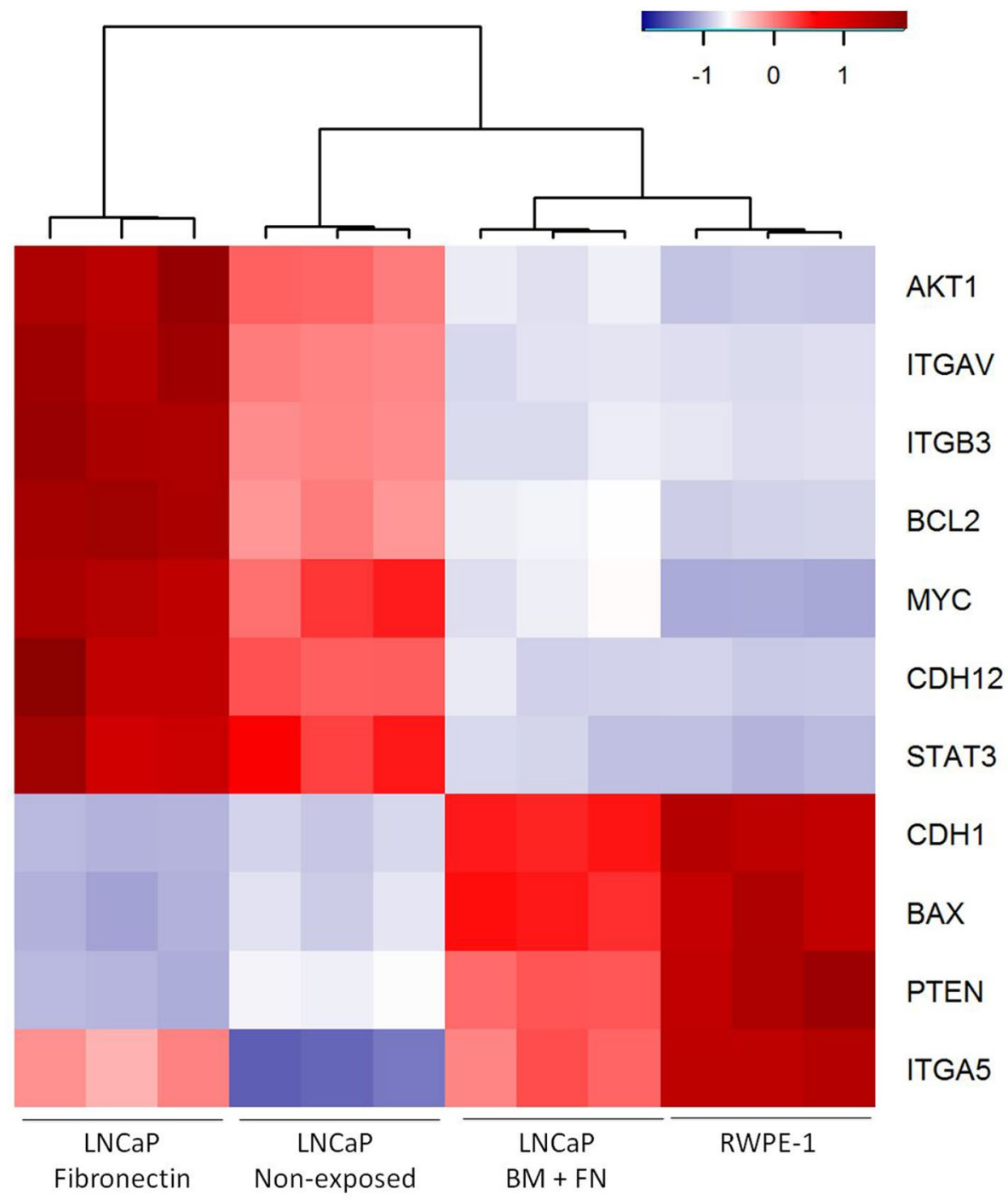

However, in primary tumor sites, tumor cells not only interact with FN, but also with other ECM elements. We therefore examined the impact of exposing our LNCaP cell model to the combination of FN and a basement membrane extract. In this environment, LNCaP cells displayed a differential expression pattern of cadherins, with decreased $N$-cadherin expression and increased $E$-cadherin expression [51, 52]. Furthermore, ITGAV and ITGB3 expression levels were significantly lower than those in $\mathrm{FN}$-only exposed cells as well as in non-exposed cells, revealing basement membrane extract attenuating role in the primary effects of FN on $\mathrm{LNCaP}$ cells gene expression.

In accordance with this new expression pattern of cell surface receptors, genes related to cell survival and invasiveness also displayed altered expression, but in an opposite way when compared to those in cells exposed only to FN. LNCaP cells in the presence of a basement membrane extract and FN showed decreased expression of AKT1, STAT3, MYC, and $B C L 2$; while expression of $B A X$, a pro-apoptotic gene, and PTEN, a gene that could sensitize LNCaP cells to an apoptotic stimuli [53], were significantly elevated. This way, the presence of the basement membrane components (Geltrex ${ }^{\circledR}$ content: laminin, type IV collagen, heparin/heparin sulfate proteoglycan, and entactin/nidogen, with reduced growth factor) seems to restrain the malignant and metastatic potential of $\mathrm{LNCaP}$ previously highlighted with exposure to FN. In these sense, our findings reinforce the results already found for breast cancer [35, 54-56] and contribute to emphasize these results also for prostate cancer in showing that a more complex ECM created a rich microenvironment favoring intercellular connections and the correction of malignant behavior. Thus, our findings show that the role of FN depends on the interactions between tumor cells and their substrates, corroborating the findings of Ramos et al. [57], who reported that changes in the microenvironment could cause a differential effect of FN on cell migration.

To further elucidate this idea, we performed a hierarchical clustering analysis with the LNCaP under the 
two different exposure conditions and the non-malignant RWPE-1 cells. Interestingly, results showed that the gene expression profile of LNCaP cells exposed to a more enriched ECM was more similar to that of RWPE-1 cells [58], while LNCaP cells exposed only to FN seemed to have acquired a more aggressive behavior, underlining that FN favors tumor growth, survival, and metastatic progression. This is especially important in the context of circulating tumor cells' biology, since it becomes evident that FN may play a role not only in angiogenesis stimulation [41], but may also sustain survival and proliferation of tumor cells within the blood vessels.

In conclusion, this study shows that the role of FN in prostate cancer is a function of the composition of the surrounding microenvironment. Our results provide the groundwork for future research addressing the role of FN signaling in tumor growth, particularly in the context of cancer evolution/progression from a solid primary tumor to a transitory circulating state.

Acknowledgements This article comprises part of the Master dissertation of BM, supported by FAPESP (São Paulo Research Foundation) funding (\#Grants 2014/25702-0 and 2013/26114-2).

\section{Compliance with ethical standards}

Conflict of interest The authors have no conflicts of interest.

\section{References}

1. Torre LA, Bray F, Siegel RL, Ferlay J, Lortet-Tieulent J, Jemal A (2015) Global cancer statistics, 2012. CA Cancer J Clin 65:87-108

2. Welch HG, Albertsen PC (2009) Prostate cancer diagnosis and treatment after the introduction of prostate-specific antigen screening: 1986-2005. J Natl Cancer Inst 101:1325-1329

3. Brower V (2007) Researchers tackle metastasis, cancer's last frontier. J Natl Cancer Inst 99:109-111

4. Palumbo A, Ferreira LB, Reis de Souza PAVV, Oliveira FL de, Pontes B, Viana NB et al (2012) Extracellular matrix secreted by reactive stroma is a main inducer of pro-tumorigenic features on LNCaP prostate cancer cells. Cancer Lett 321:55-64

5. Liotta LA, Kohn EC (2001) The microenvironment of the tumourhost interface. Nature 411:375-379

6. Cooper CR, Chay CH, Gendernalik JD, Lee H-L, Bhatia J, Taichman RS et al (2003) Stromal factors involved in prostate carcinoma metastasis to bone. Cancer 97:739-747

7. Quail DF, Joyce JA (2013) Microenvironmental regulation of tumor progression and metastasis. Nat Med 19:1423-1437

8. Jung H-Y, Fattet L, Yang J (2015) Molecular pathways: linking tumor microenvironment to epithelial-mesenchymal transition in metastasis. Clin Cancer Res 21:962-968

9. Friedl P, Wolf K (2003) Tumour-cell invasion and migration: diversity and escape mechanisms. Nat Rev Cancer 3:362-374

10. Datta K, Muders M, Zhang H, Tindall DJ (2010) Mechanism of lymph node metastasis in prostate cancer. Future Oncol NIH Public Access 6:823-836
11. Ye L, Kynaston HG, Jiang WG (2007) Bone metastasis in prostate cancer: molecular and cellular mechanisms. Int J Mol Med 20:103-111

12. Malik G, Knowles LM, Dhir R, Xu S, Yang S, Ruoslahti E et al (2010) Plasma fibronectin promotes lung metastasis by contributions to fibrin clots and tumor cell invasion. Cancer Res 70:4327-4334

13. Palumbo JS, Talmage KE, Massari JV, La Jeunesse CM, Flick MJ, Kombrinck KW et al (2005) Platelets and fibrinogen increase metastatic potential by impeding natural killer cell-mediated elimination of tumor cells. Blood 105:178-185

14. Im JH, Fu W, Wang H, Bhatia SK, Hammer DA, Kowalska MA et al (2004) Coagulation facilitates tumor cell spreading in the pulmonary vasculature during early metastatic colony formation. Cancer Res 64:8613-8619

15. Giancotti FG, Ruoslahti E (1999) Integrin signaling. Science 285:1028-1032

16. Stathakis NE, Fountas A, Tsianos E (1981) Plasma fibronectin in normal subjects and in various disease states. J Clin Pathol 34:504-508

17. Pankov R, Yamada KM (2002) Fibronectin at a glance. J Cell Sci 115:3861-3863

18. Zhang X, Liu S, Hu T, Liu S, He Y, Sun S (2009) Up-regulated microRNA-143 transcribed by nuclear factor kappa B enhances hepatocarcinoma metastasis by repressing fibronectin expression. Hepatology 50:490-499

19. Kaspar M, Zardi L, Neri D (2006) Fibronectin as target for tumor therapy. Int J Cancer 118:1331-1339

20. Barilla ML, Carsons SE (2000) Fibronectin fragments and their role in inflammatory arthritis. Semin Arthritis Rheum 29:252-265

21. Janković MM, Kosanović MM (2008) Fibronectin pattern in benign hyperplasia and cancer of the prostate. Dis Markers 25:49-58

22. Horoszewicz JS, Leong SS, Kawinski E, Karr JP, Rosenthal H, Chu TM et al (1983) LNCaP model of human prostatic carcinoma. Cancer Res 43:1809-1818

23. Moroz A, Delella FK, Lacorte LM, Deffune E, Felisbino SL (2013) Fibronectin induces MMP2 expression in human prostate cancer cells. Biochem Biophys Res Commun 430:1319-1321

24. Schroeder A, Mueller O, Stocker S, Salowsky R, Leiber M, Gassmann M et al (2006) The RIN: an RNA integrity number for assigning integrity values to RNA measurements. BMC Mol Biol $7: 3$

25. Livak KJ, Schmittgen TD (2001) Analysis of relative gene expression data using real-time quantitative PCR and the $2-\Delta \Delta C_{\mathrm{t}}$ method. Methods 25:402-408

26. Riedl SJ, Salvesen GS (2007) The apoptosome: signalling platform of cell death. Nat Rev Mol Cell Biol 8:405-413

27. Zhu ML, Kyprianou N (2010) Role of androgens and the androgen receptor in epithelial-mesenchymal transition and invasion of prostate cancer cells. FASEB J 24:769-777

28. Strohmeyer N, Bharadwaj M, Costell M, Fässler R, Müller DJ (2017) Fibronectin-bound $\alpha 5 \beta 1$ integrins sense load and signal to reinforce adhesion in less than a second. Nat Mater 16:1262-1270

29. Cavallaro U, Christofori G (2004) Cell adhesion and signalling by cadherins and Ig-CAMs in cancer. Nat Rev Cancer 4:118-132

30. Matter ML, Ruoslahti E (2001) A signaling pathway from the alpha5beta1 and alpha (v) beta3 integrins that elevates bcl-2 transcription. J Biol Chem 276:27757-27763

31. Manning BD, Toker A (2017) AKT/PKB signaling: navigating the network. Cell 169:381-405

32. Kale J, Osterlund EJ, Andrews DW (2018) BCL-2 family proteins: changing partners in the dance towards death. Cell Death Differ 25:65-80

33. Frantz C, Stewart KM, Weaver VM (2010) The extracellular matrix at a glance. J Cell Sci 123:4195-4200 
34. Glentis A, Oertle P, Mariani P, Chikina A, El Marjou F, Attieh Y et al (2017) Cancer-associated fibroblasts induce metalloproteaseindependent cancer cell invasion of the basement membrane. Nat Commun 8:924

35. Bissell MJ, Hines WC (2011) Why don't we get more cancer? A proposed role of the microenvironment in restraining cancer progression. Nat Med 17:320-329

36. Ruoslahti E (1984) Fibronectin in cell adhesion and invasion. Cancer Metastasis Rev 3:43-51

37. Steel DM, Harris H (1989) The effect of antisense RNA to fibronectin on the malignancy of hybrids between melanoma cells and normal fibroblasts. J Cell Sci 93(Pt 3):515-524

38. Jia D, Entersz I, Butler C, Foty RA (2012) Fibronectin matrixmediated cohesion suppresses invasion of prostate cancer cells. BMC Cancer 12:94

39. Pentyala SN, Whyard TC, Waltzer WC, Meek AG, Hod Y (1998) Androgen induction of urokinase gene expression in LNCaP cells is dependent on their interaction with the extracellular matrix. Cancer Lett 130:121-126

40. Fornaro M, Plescia J, Chheang S, Tallini G, Zhu Y-M, King M et al (2003) Fibronectin protects prostate cancer cells from tumor necrosis factor-alpha-induced apoptosis via the AKT/survivin pathway. J Biol Chem 278:50402-50411

41. Von Au A, Vasel M, Kraft S, Sens C, Hackl N, Marx A et al (2013) Circulating fibronectin controls tumor growth. Neoplasia Neoplasia Press 15:925-938

42. Knowles LM, Malik G, Pilch J (2013) Plasma fibronectin promotes tumor cell survival and invasion through regulation of $\mathrm{Tie}_{2}$. J Cancer 4:383-390

43. Jennbacken K, Tesan T, Wang W, Gustavsson H, Damber J-E, Welén K (2010) N-cadherin increases after androgen deprivation and is associated with metastasis in prostate cancer. Endocr Relat Cancer 17:469-479

44. Chen X, Sievers E, Hou Y, Park R, Tohme M, Bart R et al (2005) Integrin alpha $v$ beta 3 -targeted imaging of lung cancer. Neoplasia 7:271-279

45. Schneider JG, Amend SR, Weilbaecher KN (2011) Integrins and bone metastasis: integrating tumor cell and stromal cell interactions. Bone 48:54-65

46. Morgan S, Gower (2000) Fibronectin influences cellular proliferation and apoptosis similarly in $\mathrm{LNCaP}$ and $\mathrm{PC}-3$ prostate cancer cell lines. Urol Oncol 5:155-159

47. Scott G, Cassidy L, Busacco A (1997) Fibronectin suppresses apoptosis in normal human melanocytes through an integrindependent mechanism. J Investig Dermatol 108:147-153
48. Pullan S, Wilson J, Metcalfe A, Edwards GM, Goberdhan N, Tilly J et al (1996) Requirement of basement membrane for the suppression of programmed cell death in mammary epithelium. J Cell Sci 109:631-642

49. Bernard D, Pourtier-Manzanedo A, Gil J, Beach DH (2003) Myc confers androgen-independent prostate cancer cell growth. J Clin Investig 112:1724-1731

50. Asadi FK, Sharifi R (1995) Effects of sex steroids on cell growth and C-myc oncogene expression in $\mathrm{LN}-\mathrm{CaP}$ and DU-145 prostatic carcinoma cell lines. Int Urol Nephrol 27:67-80

51. Umbas R, Isaacs WB, Bringuier PP, Schaafsma HE, Karthaus HF, Oosterhof GO et al (1994) Decreased E-cadherin expression is associated with poor prognosis in patients with prostate cancer. Cancer Res 54:3929-3933

52. Tomita K, van Bokhoven A, van Leenders GJ, Ruijter ET, Jansen $\mathrm{CF}$, Bussemakers MJ et al (2000) Cadherin switching in human prostate cancer progression. Cancer Res 60:3650-3654

53. Yuan X-J, Whang YE (2002) PTEN sensitizes prostate cancer cells to death receptor-mediated and drug-induced apoptosis through a FADD-dependent pathway. Oncogene 21:319-327

54. Howlett AR, Petersen OW, Steeg PS, Bissell MJ (1994) A novel function for the nm23-H1 gene: overexpression in human breast carcinoma cells leads to the formation of basement membrane and growth arrest. J Natl Cancer Inst 86:1838-1844

55. Dubois C, Dufour R, Daumar P, Aubel C, Szczepaniak C, Blavignac $C$ et al (2017) Development and cytotoxic response of two proliferative MDA-MB-231 and non-proliferative SUM1315 three-dimensional cell culture models of triple-negative basallike breast cancer cell lines. Oncotarget 8:95316-95331

56. Kenny PA, Bissell MJ (2003) Tumor reversion: correction of malignant behavior by microenvironmental cues. Int J Cancer 107:688-695

57. Ramos G, de O, Bernardi, Lauxen L, Sant'Ana Filho I, Horwitz M, Lamers AR ML (2016) Fibronectin modulates cell adhesion and signaling to promote single cell migration of highly invasive oral squamous cell carcinoma. PLoS ONE 11:e0151338

58. Webber MM, Bello D, Quader S (1996) Immortalized and tumorigenic adult human prostatic epithelial cell lines: characteristics and applications. Part I. Cell markers and immortalized nontumorigenic cell lines. Prostate 29:386-394 